\title{
Exploring the NOx reduction potential of Miller cycle and EGR on a HD diesel engine operating at full load
}

\author{
Guan W, Pedrozo V, Zhao H, Ban Z and Lin T
}

\begin{abstract}
The reduction in nitrogen oxides (NOx) emissions from heavy-duty diesel engines requires the development of more advanced combustion and control technologies to minimize the total cost of ownership (TCO), which includes both the diesel fuel consumption and the aqueous urea solution used in the selective catalytic reduction (SCR) aftertreatment system. This drives an increased need for highly efficient and clean internal combustion engines. One promising combustion strategy that can curb NOx emissions with a low fuel consumption penalty is to simultaneously reduce the in-cylinder gas temperature and pressure. This can be achieved with Miller cycle and by lowering the in-cylinder oxygen concentration via exhaust gas recirculation (EGR). The combination of Miller cycle and EGR can enable a low TCO by minimizing both the diesel fuel and urea consumptions.
\end{abstract}

In this work, Miller cycle with late intake valve closing (IVC) and EGR technology were investigated on a single cylinder common rail heavy-duty diesel engine at the high load operation of 24 bar net indicated mean effective pressure. The experiments were performed with a constant intake manifold pressure of 3 bar while optimizing the start of diesel injection to keep the peak in-cylinder pressure limit of 180 bar. The aqueous urea solution consumption in the SCR aftertreatment system was estimated to evaluate the effectiveness of the strategies in terms of TCO. The calculation was based on the engine-out NOx emissions and the Euro VI NOx limit. The results revealed that the use of the Miller cycle without EGR reduced NOx emissions by $35 \%$ and the net indicated efficiency by $4 \%$ when compared to the case with the baseline IVC at -178 crank angle degrees (CAD) after top dead center (ATDC). The introduction of $8 \%$ EGR decreased the levels of NOx by $54 \%$ while maintaining similar net indicated efficiency at the baseline IVC. The combination of Miller cycle with an IVC at -127 CAD ATDC and an EGR rate of $8 \%$ achieved the best trade-off between NOx and ISFC, decreasing the NOx levels by $57 \%$ and the fuel consumption by $1.6 \%$ compared to the baseline case. Soot emissions were maintained below the Euro VI limit of $0.01 \mathrm{~g} / \mathrm{kW}$ h. Carbon monoxide emissions were maintained at low levels except for the combination of an IVC at 114 and an EGR rate of 8\%. Unburned hydrocarbon emissions were slightly decreased with EGR and late IVCs likely due to relatively longer ignition delays and higher exhaust gas temperature. Overall, the analysis showed that the combination of Miller cycle with an IVC at -127 CAD ATDC and 8\%EGR achieved the lowest total fluid consumption despite the reduction in net indicated thermal efficiency.

\section{Introduction}

Diesel engines have been the main power source in transportation sectors owing to their high torque output and superior thermal efficiency. However, conventional diesel combustion produces harmful exhaust emissions, particularly NOx and smoke, due to the presence of high local in-cylinder equivalence ratio and temperature during the mixing-controlled combustion [1]. The application of more stringent exhaust emissions and carbon dioxide $\left(\mathrm{CO}_{2}\right)$ regulations have driven the development of cleaner and more efficient internal combustion engines [2]. In recent years, the main research focus has been on the reduction of NOx and smoke emissions while maintaining or increasing the engine efficiency. This has been achieved by the combination of in-cylinder measures and exhaust aftertreatment technologies, such as the SCR system [3].

However, there is an optimum balance between in-cylinder and aftertreatment control of NOx emissions, which is attained by minimizing the diesel fuel consumption and the aqueous urea solution used in the SCR system [4]. Therefore, it is favorable to reduce emissions and increase engine efficiency by an optimization of in-cylinder combustion process and the development of high efficiency aftertreatment system in order to reduce the total cost of ownership.

As for the in-cylinder measures, low temperature combustion (LTC) concepts such as homogenous charge compression ignition (HCCI) and partially premixed charge compression ignition (PCCI) have shown potential to significantly reduce engine-out NOx and smoke emissions at the expense of lower engine efficiency and higher emissions of unburned hydrocarbon (HC) and carbon monoxide (CO) $[5,6]$. These LTC strategies are usually achieved by high levels of EGR, which allow for longer ignition delay and lower combustion temperatures [7]. However, the use of elevated EGR rates might not be practical at high loads because of the greater demand on the boosting system and the cooling system of the engine in order to maintain a reasonable excess of air while keeping an acceptable peak in-cylinder pressure [8].

Alternatively, Miller cycle can be used in an attempt to decrease the EGR requirements. This in-cylinder strategy can reduce NOx emissions by lowering the effective compression ratio via early or late IVCs while maintaining the original expansion ratio. Initially, Miller cycle was used to improve thermal efficiency by avoiding knocking combustion in gasoline engines [9]. In recent years, it has received more attention in diesel engines due to a potential NOx emissions reduction benefit obtained by lowering the peak combustion temperatures [10-12]. 
Rinaldini et al. [13] carried out an experimental and numerical study to assess the potential and the limits of Miller cycle in a four-cylinder diesel engine. A significant reduction in NOx emissions was achieved at high load with small fuel consumption penalty. In the European Driving Cycle, the employment of Miller cycle reduced NOx emissions by $25 \%$ and soot emissions by $60 \%$ at the expense of fuel efficiency penalty of $2 \%$. The NOx emissions reduction observed in the Miller cycle was mainly because of the lower combustion temperatures, while significant soot reduction was explained by the higher values of air/fuel ratio as a consequence of the higher boosting level. Wang et al. [14] experimentally investigated the feasibility of reducing NOx emissions by Miller cycle on a diesel engine. The Miller cycle via early IVCs also decreased NOx emissions. In addition, previous research $[15,16]$ found that Miller cycle had great potential in decreasing the combustion pressure and temperatures, and thus NOx emissions, at high engine loads.

Additionally, some studies have investigated the combined use of Miller cycle with EGR on engine efficiency and emissions [17,18]. Verschaeren et al. [19] performed an experimental study of EGR with earlier IVC timings for NOx emissions control on a heavy-duty diesel engine operation at high loads. The results revealed that NOx was reduced by nearly $70 \%$ with an increase in smoke and CO emissions. However, unburned HC emissions decreased likely due to the retarded combustion process and higher exhaust gas temperatures, increasing the probability for HC oxidation further in the expansion stroke. Benajes et al. [15] studied the effect of early IVCs at full load in a heavy duty diesel engine. The in-cylinder oxygen concentration was maintained constant by varying the EGR rate at a constant intake pressure. Although NOx emissions were reduced, an increment in soot and CO emissions were observed due to the lower in-cylinder gas density and oxygen availability, which led to lower flame temperature and longer mixing-controlled combustion. Moreover, the important changes in the P-V diagram introduced by the lower effective compression ratio and slower combustion process reduced the engine efficiency.

In addition to the challenges observed in minimizing the NOx emissions, peak in-cylinder pressure limitation is another constraint for modern turbocharged diesel engines when operating at high loads. Miller cycle reduces the maximum in-cylinder pressure by delaying the initiation of the compression process. This allows for the application of more advanced diesel injection timing, higher fuel injection pressures and increased boost pressures to improve the engine efficiency.

Kovács et al. [20] investigated the Miller cycle in the upper load range of a heavy-duty diesel engine in order to reduce the peak incylinder pressure. The pressure reserve was used to combine with further measures while maintaining the maximum in-cylinder pressure of baseline case. When applied with higher fuel injection pressure, Miller cycle increased the engine efficiency by up to $10 \%$. In the combination of Miller cycle with higher boost pressure at constant CA50 and NOx emission by adjusting the start of injection and EGR rate respectively, soot and CO emissions were significantly reduced, and thus a significant improvement in the trade-offs between

NOx, soot and CO. The previous investigations have shown that Miller cycle and EGR strategies can be effective in minimizing the engine-out NOx emissions from diesel engines. The lower effective compression ratio and oxygen availability, however, can adversely affect the fuel conversion efficiency and thus the TCO. In addition to the fuel efficiency, the TCO will be also affected by the operating cost of the aftertreatment system in terms of the urea consumption. Therefore, the optimization of the combustion process with Miller cycle and low to moderate levels of EGR is necessary in order to explore the NOx reduction capability while decreasing the TCO of SCR equipped vehicles.

The focus of this work is to explore the NOx emissions reduction potential of EGR and Miller cycle with late IVCs on a heavy-duty diesel engine equipped with a variable valve actuation (VVA) system on the intake camshaft and a high pressure common rail injection system. The investigation was carried out at a speed of $1250 \mathrm{rpm}$ and a load of 24 bar net indicated mean effective pressure (IMEP) while maintaining intake and exhaust pressures constant. The effects of Miller cycle and EGR on engine combustion, emissions, and efficiency were discussed. In the last section, the aqueous urea solution consumption in the SCR system was estimated based on the engine-out NOx emissions and the Euro VI NOx limit [21]. The overall exhaust emissions, total fluid consumption, and the corrected net indicated efficiency were analyzed and compared at the maximum net indicated efficiency, in order to determine the most effective strategy in terms of TCO.

\section{Experimental setup}

The study was performed on a single-cylinder four-stroke heavy-duty diesel engine equipped with a common rail diesel injection system. The engine was coupled to an eddy current dynamometer. The test setup is shown in Figure 1 and the specifications of the research engine are given in Table 1.

Table 1. Specifications of test engine.
\begin{tabular}{|l|c|}
\hline Displaced Volume & $2026 \mathrm{~cm}^{3}$ \\
\hline Stroke & $155 \mathrm{~mm}$ \\
\hline Bore & $129 \mathrm{~mm}$ \\
\hline Connecting Rod Length & $256 \mathrm{~mm}$ \\
\hline Geometric Compression Ratio & 16.8 \\
\hline Number of Valves & 4 \\
\hline Piston Type & Stepped-lip bowl \\
\hline Diesel Injection System & Bosch common rail \\
\hline Nozzle Design & 8 holes, included spray angle of $150^{\circ}$ \\
\hline Maximum Fuel Injection Pressure & 2200 bar \\
\hline Maximum In-cylinder Pressure & 180 bar \\
\hline
\end{tabular}

A hydraulic lost motion VVA system was installed on the intake camshaft to control the intake valve events. A displacement sensor was installed on the top of the intake valve spring retainer and was used to measure the intake valve lift. As shown in the engine test setup, the pressurized intake air pressure was supplied to the engine

Page 2 of 19 


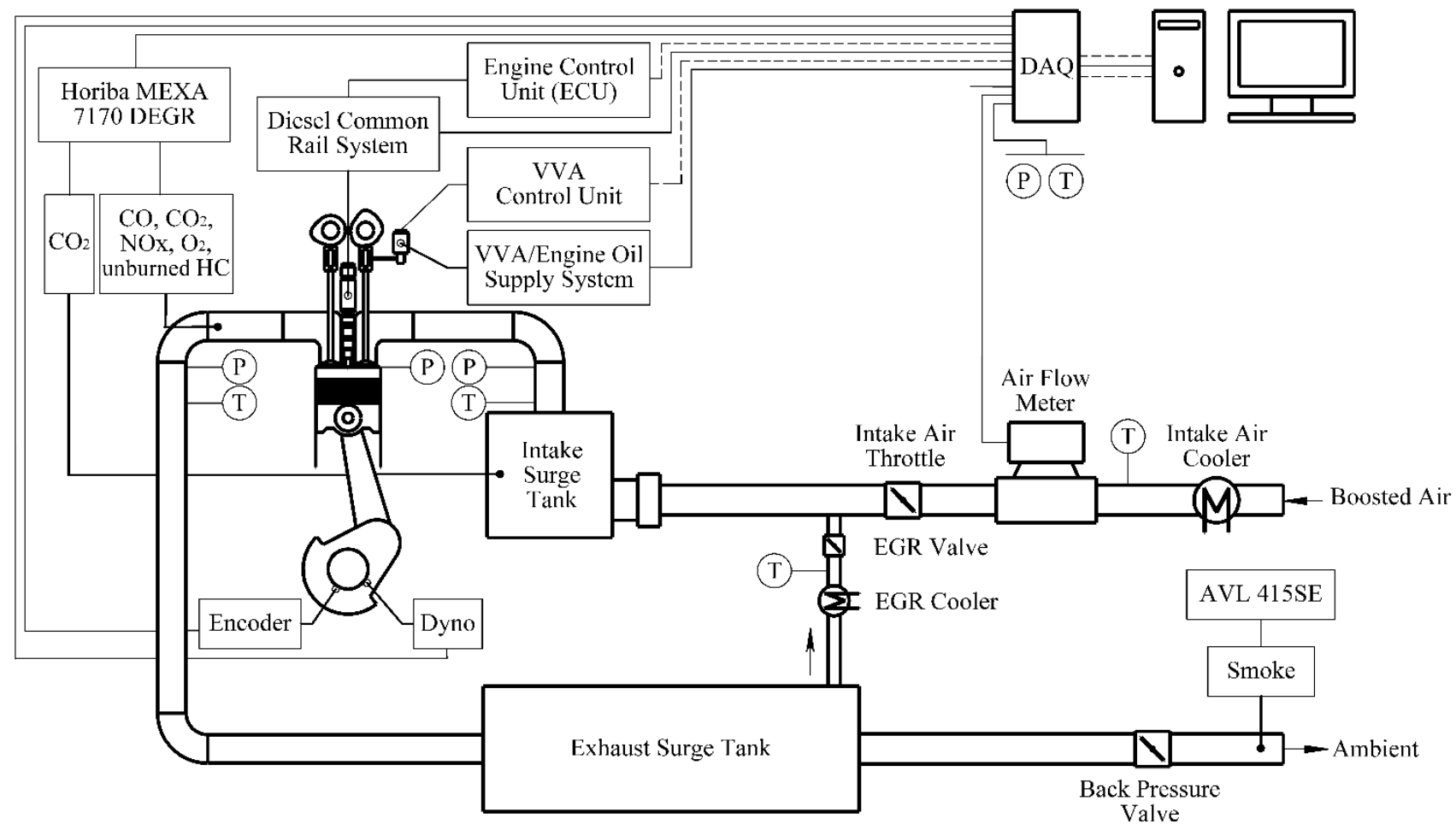

Figure 1. Schematic of the single cylinder HD engine experimental setup.

by an external supercharger with closed loop control. A thermal mass flow meter was used to measure the intake mass flow and an intake throttle valve provided fine control over the intake manifold air pressure. Two large-volume surge tanks were installed in the intake and exhaust manifolds to damp out the pressure fluctuations. A butterfly valve located downstream of the exhaust surge tank was used to control the exhaust back pressure. Two piezo-resistive pressure transducers were installed to measure the instantaneous intake and exhaust manifold pressures. External cooled EGR was introduced into the engine upstream of the intake surge tank using a pulse width modulation controlled poppet valve and the pressure differential between the intake and exhaust. Water cooled heat exchangers were used to control the temperatures of the intake air, EGR, as well as engine coolant and lubrication oil which were driven independently by external electric motors.

During the test, the diesel fuel was supplied to the engine using a solenoid valve injector and a high pressure pump with a maximum fuel pressure of 2200 bar. A dedicated electronic control unit (ECU) was used to control fuel injection parameters such as injection pressure, start of injection (SOI), and the number of injections. Two Coriolis flow meters were used to measure the fuel consumption by considering the total fuel supplied to and from the high pressure pump and diesel injector.

The in-cylinder pressure was measured using a piezo-electric pressure sensor mounted in the cylinder head. The in-cylinder pressure data was averaged over 200 engine cycles and used to calculate the apparent heat release rate (HRR) and combustion characteristics [1]. In this study, the CA50 (combustion phasing) was defined as the crank angle when the fuel mass fraction burned (MFB) reached $50 \%$. Ignition delay was defined as the period between the SOI and the start of combustion, denoted as $0.3 \%$ MFB point of the average cycle. The specifications of measurement devices are shown in the Appendix A.
The exhaust gases (NOx, $\mathrm{HC}, \mathrm{CO}$, and $\mathrm{CO}_{2}$ ) were measured using a Horiba MEXA-7170-DEGR emissions analyzer. A high pressure sampling module and a heated line were used to enable high pressure sampling and avoid condensation, respectively. The smoke concentration was measured downstream of the exhaust back pressure valve using an AVL 415SE smoke meter, and thereafter converted from filter smoke number (FSN) to $\mathrm{mg} / \mathrm{m}^{3}$ [22]. All the exhaust gas components were converted to net indicated specific gas emissions (in $\mathrm{g} / \mathrm{kWh}$ ) according to [21]. The EGR rate was defined as the ratio of the measured $\mathrm{CO}_{2}$ concentration in the intake surge tank to the $\mathrm{CO}_{2}$ concentration in the exhaust manifold as

$$
\text { EGR rate }=\frac{\left(\mathrm{CO}_{2} \%\right)_{\text {intake }}}{\left(\mathrm{CO}_{2} \%\right)_{\text {exhaust }}} \times 100 \%
$$

where the $\left(\mathrm{CO}_{2} \%\right)_{\text {intake }}$ and $\left(\mathrm{CO}_{2} \%\right)_{\text {exhaust }}$ are the $\mathrm{CO}_{2}$ concentration in the intake and exhaust manifolds, respectively.

\section{Methodology}

The experimental investigation was performed at an engine speed of $1250 \mathrm{rpm}$ and full load of 24 bar IMEP. This operating condition is characterized by high peak in-cylinder pressure and combustion temperatures and hence high NOx formation.

Table 2 summarizes the testing conditions for the baseline operation as well as for the Miller cycle operation using $0 \%$ and $8 \%$ EGR. The diesel SOI was swept and optimized up against the in-cylinder pressure limit of $180 \mathrm{bar}$ in order to achieve the maximum net indicated thermal efficiency. However, the case of IVC at-114 CAD ATDC with 8\%EGR can only be performed with the most advanced SOI as the smoke number was limited to $1 \mathrm{FSN}$ over the test.

The injection pressure (Pinj) was held constant at 1800 bar except for the case with an IVC at -114 CAD ATDC and an EGR rate of 8\%. In

Page 3 of 19 
this case, an injection pressure of 2200 bar was used to overcome the combustion instability and excessive smoke. Stable engine operation was determined by controlling the coefficient of variation of IMEP (COV_IMEP) below 3\%. During the tests, the coolant and oil temperatures were kept within $85 \pm 2{ }^{\circ} \mathrm{C}$. Oil pressure was maintained within $4.0 \pm 0.1$ bar.

All valve events were determined at $1 \mathrm{~mm}$ valve lift and the maximum intake valve lift was held constant at $14 \mathrm{~mm}$. The intake and exhaust valve lift profiles used for the baseline and Miller cycle operations are illustrated in Figure 2. The intake valve opening (IVO) was set at 367 CAD ATDC while the IVC was delayed from -178 CAD ATDC in baseline case to -127 and -114 CAD ATDC in the Miller cycle strategies.

Table 2. Engine testing conditions.

\begin{tabular}{|c|c|c|c|c|c|}
\hline Speed & \multicolumn{5}{|c|}{$1250 \mathrm{rpm}$} \\
\hline IMEP & \multicolumn{5}{|c|}{24 bar } \\
\hline $\begin{array}{l}\text { Intake } \\
\text { Pressure }\end{array}$ & \multicolumn{5}{|c|}{$3.0 \mathrm{bar}$} \\
\hline $\begin{array}{l}\text { Exhaust } \\
\text { Pressure } \\
\end{array}$ & \multicolumn{5}{|c|}{3.1 bar } \\
\hline \multirow{2}{*}{ IVC } & Baseline & \multicolumn{4}{|c|}{ Miller cycle } \\
\hline & $\begin{array}{c}-178 \\
\text { CAD ATDC } \\
\end{array}$ & \multicolumn{2}{|c|}{$\begin{array}{c}-127 \\
\text { CAD ATDC } \\
\end{array}$} & \multicolumn{2}{|c|}{$\begin{array}{c}-114 \\
\text { CAD ATDC } \\
\end{array}$} \\
\hline ECR & 16.8 & \multicolumn{2}{|c|}{15.9} & \multicolumn{2}{|c|}{15.2} \\
\hline $\begin{array}{l}\text { Injection } \\
\text { Pressure } \\
\end{array}$ & \multicolumn{4}{|c|}{ 1800bar } & $2200 \mathrm{bar}$ \\
\hline EGR Rate & $0 \%$ & $0 \%$ & $8 \%$ & $0 \%$ & $8 \%$ \\
\hline
\end{tabular}

The start of the compression in the cylinder was delayed with later IVCs, lowering effective compression ratio (ECR). In this study, the ECR was calculated as

$$
E C R=\frac{V i v c_{-} e f f}{V t d c}
$$

where $V_{t d c}$ is the in-cylinder volume at TDC position, and $V_{i v c_{-} e f f}$ is the effective in-cylinder volume where the in-cylinder gas pressure is equivalent to the intake manifold pressure, rather than the in-cylinder volume at IVC [23].

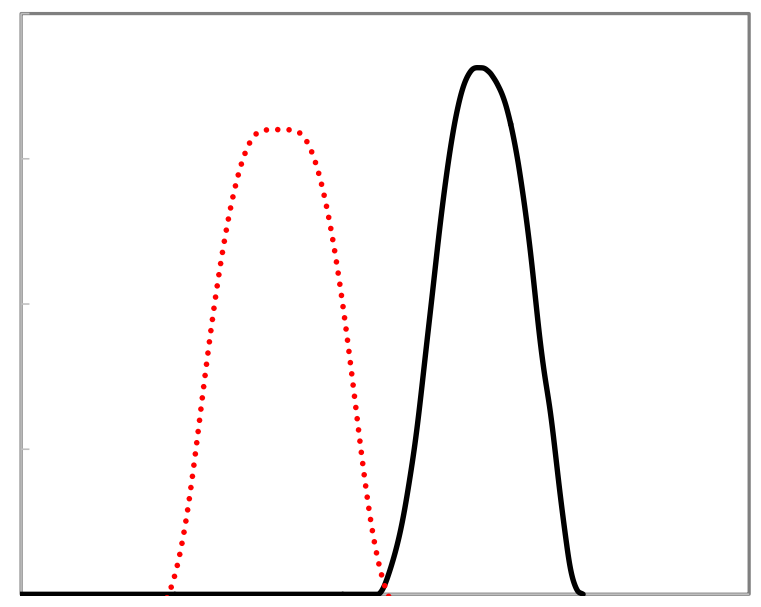

Figure 2. Fixed exhaust camshaft timing and variable intake valve lift profiles with VVA.

Page 4 of 19

\section{Results and discussion}

\section{Analysis of the in-cylinder pressure and heat release rate}

Figure 3 shows the in-cylinder pressure and heat release rate (HRR) for both the baseline (IVC at -178 CAD ATDC) and the Miller cycle (IVCs at -127 and -114 CAD ATDC) operations with and without EGR. The comparison was performed with a constant SOI at -3 CAD ATDC. Compared to the baseline case, the Miller cycle strategy decreased the compression pressure as a result of the reduction of incylinder air flow rate and density. The maximum in-cylinder pressure (Pmax) difference between the baseline and the Miller cycle was approximately 25 bar at the end of compression. The lower compression pressure led to a significant reduction in peak incylinder pressure and heat release rate during the combustion process.

The use of EGR with baseline IVC showed less impact on the incylinder pressure and peak heat release rate compared to the Miller cycle strategy, due to the replacement of the fresh air with recirculated exhaust gas instead of reducing the total in-cylinder mass in the Miller cycle strategy. Overall, the combined strategy of Miller cycle and EGR achieved the highest reduction in the peak in-cylinder pressure and the heat release rate due to the reduced in-cylinder air flow caused by the late IVC as well as the dilution effect and higher heat capacity introduced by EGR.

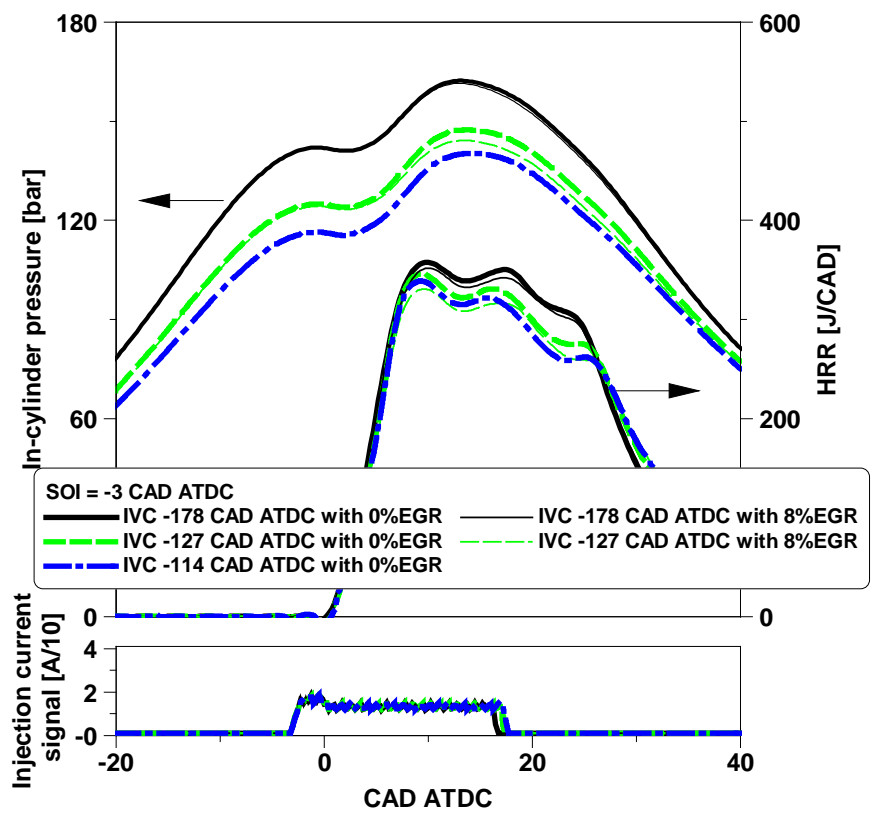

Figure 3. The effect of Miller cycle and EGR on in-cylinder pressure and HRR at the same diesel SOI.

The diesel SOI is an important factor in maximizing engine efficiency and curbing emissions. In order to achieve high net indicated efficiency, the SOI should be optimized for the main heat release to take place immediately after TDC. Thus, the SOI was swept for various combustion control strategies. The data in Figure 4 depicts the sensitivity of maximum in-cylinder pressure and net indicated efficiency with respect to SOI at different IVCs with and without EGR. The selected calibrations for different combustion control strategies are denoted with a green circle and will be analyzed later on. 
As shown in Figure 4, the Pmax and net indicated efficiency increased linearly as the SOI was advanced for the range of injection timings tested. The maximum net indicated efficiencies were achieved by the most advanced cases, which were limited by the peak in-cylinder pressure of 180 bar. Figure 5 depicts the in-cylinder pressures and heat release rates of various IVCs with and without EGR for the selected calibrations from Figure 4.

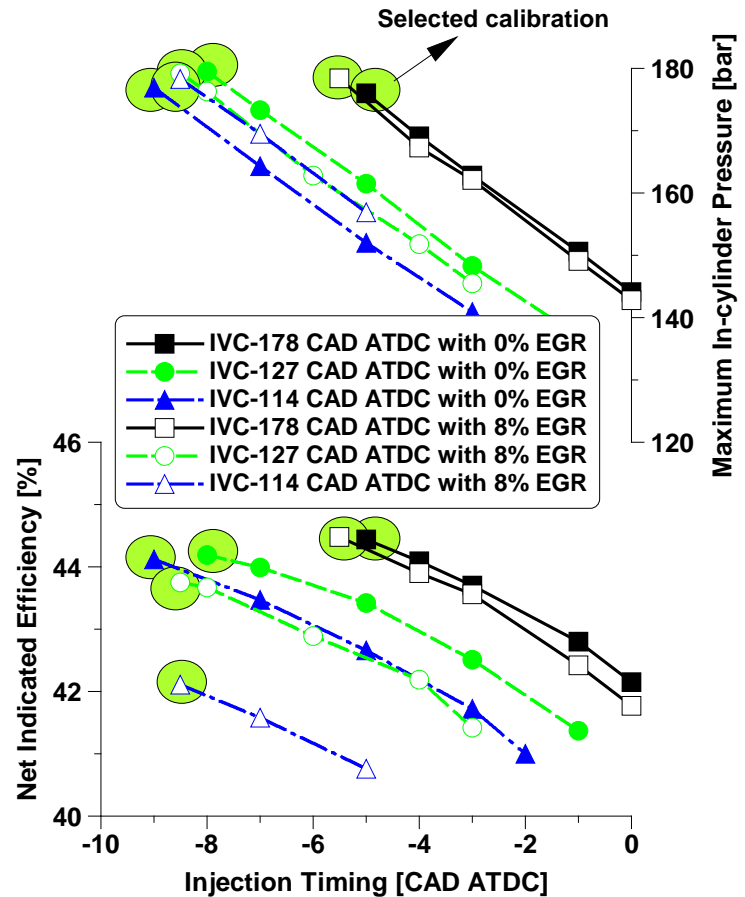

Figure 4. Pmax and net indicated efficiency vs diesel SOI for various IVCs with and without EGR.

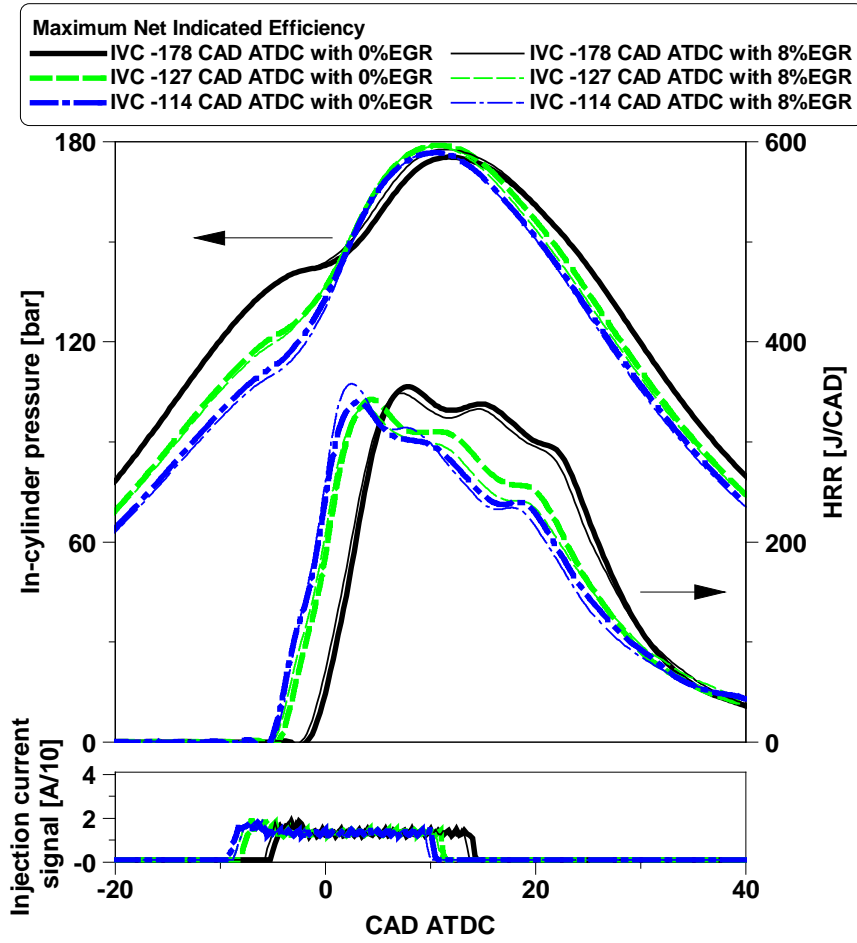

Figure 5. The effect of Miller cycle and EGR on in-cylinder pressure and HRR at the optimum diesel SOIs.

Page 5 of 19
The dilution and higher heat capacity introduced by EGR slowed down the combustion process and slightly reduced the in-cylinder pressure, as depicted in Figure 3, allowing for a more advanced SOI to maximize indicated efficiency. However, the difference between the optimized (most advanced) diesel SOI with and without EGR of the baseline IVC was less significant than the Miller cycle operation. By delaying IVC, the Miller cycle enabled a more advanced diesel SOIs and earlier heat release as a result of the lower effective compression ratio. The application of a higher injection pressure in the IVC at -114 CAD ATDC with 8\%EGR required retarding CA50 due to the increased Pmax limits. Therefore, the earliest heat release was obtained with an IVC at -114 CAD ATDC with no EGR where SOI was the most advanced.

\section{The effect of Miller cycle and EGR on combustion characteristics}

Figure 6 shows the resulting heat release characteristics for the baseline operation with IVC at -178 CAD ATDC and the Miller cycle with IVC at -127 and -114 CAD ATDC. The comparison was performed with a constant SOI at -3 CAD ATDC and the most advanced SOIs of the optimum cases, with and without EGR. At the full load, the changes in ignition delay and the degree of premixed combustion are very marginal with different IVCs due to the relatively good ignition conditions [20]. A similar trend was observed in this study, the Miller cycle strategy slightly increased the ignition delay by lowering the initial pressure and temperature. The addition of EGR further prolonged the ignition delay when combining with late IVCs. The longer ignition delay in both Miller cycle and EGR strategies led to later CA50 (combustion phase), as showed in Figure 6 . With the maximum efficient cases, the reduction of in-cylinder pressure during the compression stroke allowed for more advanced diesel SOIs and earlier CA50 positions than those attained at constant SOIs.

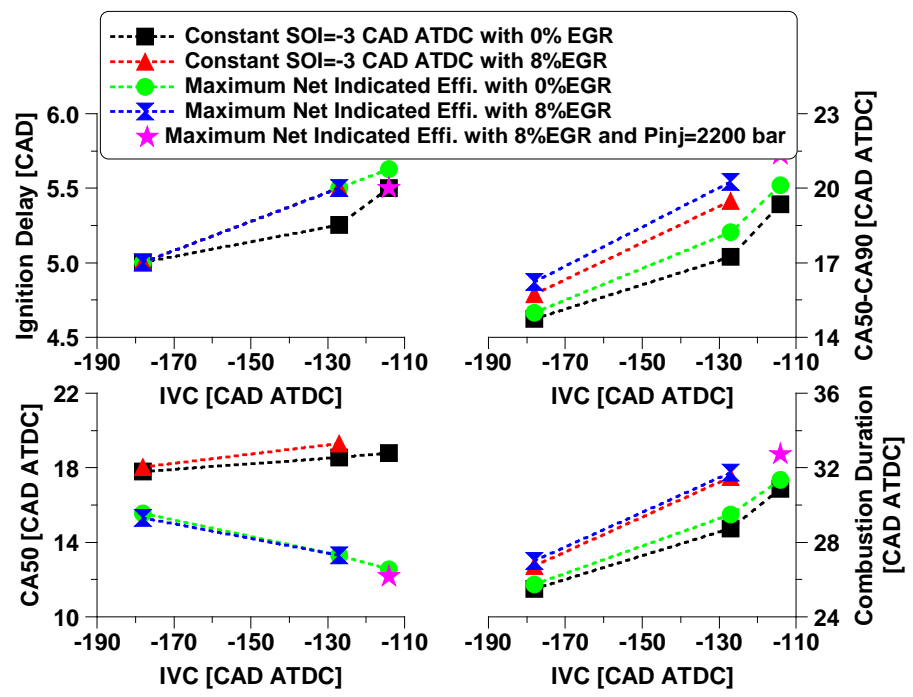

Figure 6. The effect of Miller cycle and EGR on the resulting heat release characteristics.

In addition, as a result of the reduced in-cylinder charge and the dilution effect, both Miller cycle and EGR strategies reduced the incylinder oxygen availability during the mixing-controlled combustion stage, leading to a slower later combustion process as measured by CA50-CA90. Moreover, the Miller cycle with EGR strategy yielded 
the longest mixing-controlled combustion process and combustion duration but the earliest combustion phasing measured by CA50.

\section{The effect of Miller cycle and EGR on engine performance}

Figure 7 shows that the use of Miller cycle and EGR significantly reduced the relative air/fuel ratio (lambda), especially in the cases of EGR with a constant SOI at -3 CAD ATDC. The lowest lambda below 1.2 was measured for the case with an IVC at -114 CAD ATDC and 8\%EGR despite the higher injection pressure. The more advanced SOI in the most efficient cases showed higher lambda value than those at a constant SOI as less fuel was burned to maintain the same IMEP when the indicated efficiency was increased.

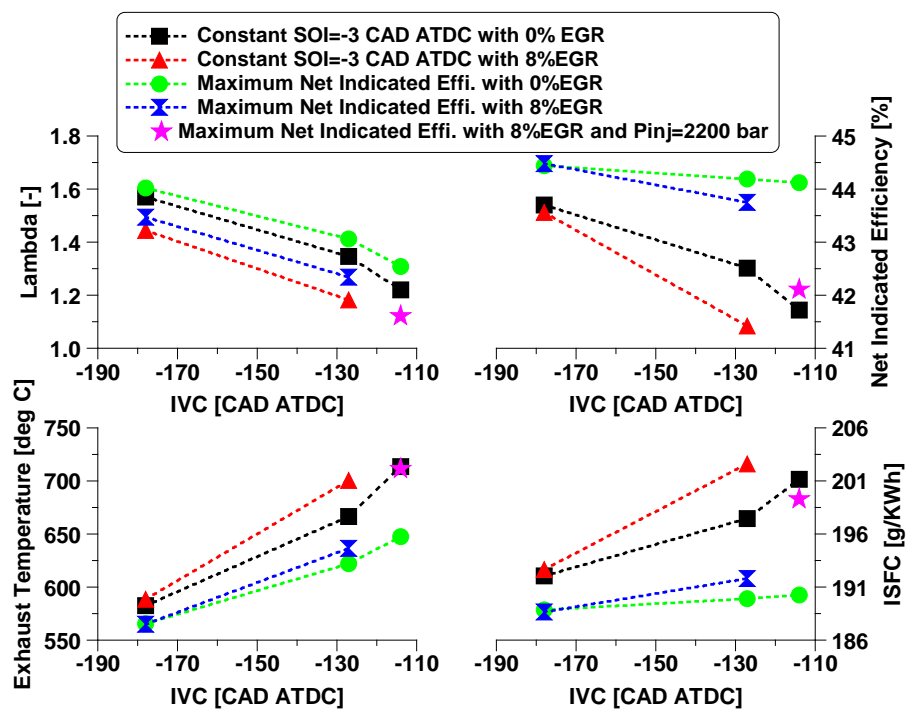

Figure 7. The effect of Miller cycle and EGR on lambda and exhaust gas temperatures.

The exhaust gas temperatures increased linearly with a decrease in lambda regardless of the strategy used. A similar relation between exhaust gas temperatures and the lambda was presented by Garg et al. [24] using intake valve closing modulation for exhaust thermal management. The Miller cycle strategies led to a notably decrease in lambda value, which in turn increased the exhaust gas temperatures. The use of EGR presented a little impact on the exhaust gas temperature when operating with the baseline IVC, which can be explained by the dilution and higher heat capacity introduced by EGR, resulting in lower in-cylinder gas temperatures [25]. Besides, the higher lambda value at baseline IVC with EGR was also the primary reason for the insignificant effect on EGT. However, the addition of EGR showed clear impact on exhaust gas temperatures when operating with Miller cycle due to the much lower lambda value with a delayed IVC.

Figure 7 also shows the net indicated efficiency and fuel consumption of the baseline and the Miller cycle at a constant and most advanced SOIs for the maximum efficient operations, with and without EGR. It can be seen that the net indicated efficiency reduced rapidly with delayed IVCs while varied slightly in the use of EGR with the baseline IVC at -178 CAD ATDC. This can be explained by the longer combustion duration in the cases with late IVCs. Another possible reason is the higher average combustion temperatures in the Miller cycle due to the reduced total in-cylinder gas heat capacity, resulting in higher heat loss to the cylinder walls. This has been presented in previous study [26] by using an one-dimensional engine simulation model to calculate the averaged in-cylinder gas temperatures and burned zone gas temperatures at 6 bar and 12 bar Page 6 of 19
IMEP, in which a higher average combustion temperature was observed in the Miller cycle strategy while the flame temperature was reduced due to the slower combustion process. As the pressure difference between intake and exhaust manifolds was kept constant during the test, the influence of pumping loss could be negligible. With the use of EGR and an IVC at -178 CAD ATDC, the net indicated efficiency decreased slightly at a constant SOI. This was the net result of these two counteracting effects of the prolonged combustion duration and the lower heat transfer loss resulted from higher heat capacity and hence lower combustion temperatures. With late IVCs, the addition of EGR has been observed to notably increase ISFC and thus lower net indicated efficiency.

Without EGR, the net indicated efficiency was significantly increased in the most efficient cases by advancing the SOIs. The high efficiency was maintained when the IVC was delayed from -178 to 114 CAD ATDC. With EGR, however, the net indicated efficiency was decreased with late IVCs even with the most advanced SOIs. In particular, the maximum reduction of net indicated efficiency by $3.8 \%$ in the most efficient cases was obtained when IVC was delayed from -127 to -114 CAD ATDC with 8\%EGR, although a higher injection pressure of 2200 bar was applied. As such, the combined effects of the net heat transfer loss and longer combustion duration as well as the late combustion process after TDC accounted for the lower net indicated efficiency in the combined strategy of Miller cycle with EGR at high engine loads.

\section{The effect of Miller cycle and EGR on emissions}

Figure 8 depicts the engine-out emissions for various IVCs with and without EGR shown as the net indicated specific values of NOx, soot, unburned HC and CO.

By delaying the IVC, the Miller cycle effectively reduced the NOx emissions primarily due to the lower in-cylinder oxygen availability and flame temperatures. In addition, the lower peak in-cylinder pressure and later combustion phasing were also beneficial to the NOx abatement. The use of EGR was more effective in abating NOx emissions than the Miller cycle strategy attributed to the particular dilution effect and higher heat capacity in decreasing flame temperature. The NOx levels were reduced from $12.8 \mathrm{~g} / \mathrm{kWh}$ in baseline case to $7.1 \mathrm{~g} / \mathrm{kW} \mathrm{h}$ in the IVC -178 with EGR. The application of Miller cycle with EGR strategy allowed for higher NOx reduction due to relatively lower oxygen availability and incylinder gas temperatures, decreasing NOx levels from $12.8 \mathrm{~g} / \mathrm{kWh}$ to $3.9 \mathrm{~g} / \mathrm{kWh}$, approximately by $69 \%$. It is noted that the NOx emissions in the most efficient cases was slightly higher than that in a constant diesel SOI due to the more advanced combustion near TDC and hence higher combustion temperatures.

The soot emissions exhibited a different trend from that of NOx emissions when using Miller cycle and EGR strategies. The soot emissions was less affected by the use of EGR in the IVC of -178 due to a sufficiently high lambda. However, an apparent increase in soot emissions was observed as the IVC was delayed to -114 CAD ATDC attributed to the significantly lower lambda, as shown in Figure 7. In the combination of Miller cycle and EGR strategy, the soot emissions increased noticeably and could be improved by advancing the SOI with an IVC at -127 CAD ATDC. However, the lambda dropped lower than 1.2 when the IVC was delayed to -114 CAD ATDC, leading to significantly higher soot emissions. The FSN values are shown in the Appendix B. 
The observed trend of CO emissions for various IVCs with and without EGR was similar to the one for soot emissions. The CO emissions increased rapidly as IVC was delayed to -114 CAD ATDC while varied slightly with EGR at the baseline IVC. The availability of oxygen in the cylinder played the dominant role on the CO emissions since the combustion temperatures at full load were sufficiently high to maintain a high combustion efficiency, regardless of the strategy used. Likewise, the CO emissions in the Miller cycle and EGR strategies were significantly improved at the most efficient cases, except for the case with IVC at -114 CAD ATDC and 8\%EGR.

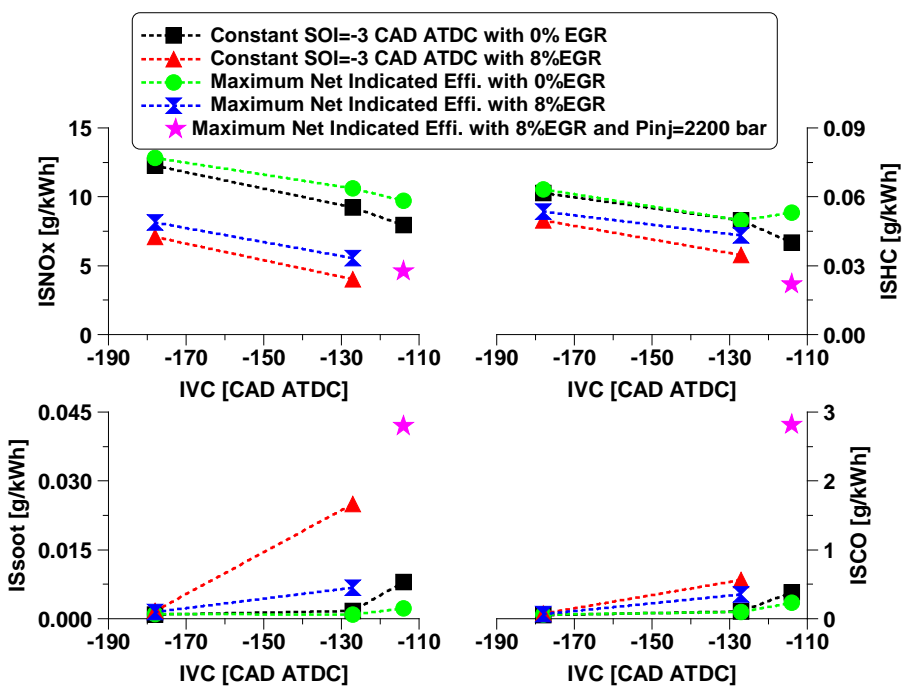

Figure 8. The effect of Miller cycle and EGR on engine emissions.

Figure 8 also shows that the HC emissions were low in all cases at this operation load. Interestingly, both EGR and Miller cycle strategies were beneficial to the reduction of unburned HC emissions possibly because of the relatively higher fuel/air equivalence ratio of the in-cylinder charge. The higher exhaust gas temperature was also one factor for the unburned $\mathrm{HC}$ reduction, due to the higher HC oxidation rate during the expansion stroke [19]. Different from the observed trend of other emissions as shown earlier, the unburned HC showed less sensitivity to the diesel SOI when varying the IVC with or without EGR. Overall, the combination of Miller cycle and EGR achieved the lowest $\mathrm{HC}$ emissions, mainly due to the highest fuel/air equivalence ratios and exhaust gas temperatures.

An improvement in the NOx-Soot and NOx-ISFC trade-off relationships was observed when applying Miller cycle and EGR strategies, as shown in Figure 9. The Miller cycle strategy alone did not has a great potential in reducing NOx emissions and accompanied with a higher fuel consumption penalty. It can be seen that NOx emissions at IVC -114 with no EGR was reduced by $35 \%$ with fuel efficiency penalty of $4 \%$ when compared to the baseline case. A higher reduction in NOx emission by $45 \%$ with small fuel efficiency penalty could be obtained by using EGR strategy with IVC at -178 CAD ATDC.

Overall, the introduction of 8\% EGR combined with Miller cycle at IVC -127 showed the best trade-off between NOx, ISFC and soot. This can be explained by the high potential of NOx reduction using EGR combined with the high capability in decreasing the peak incylinder pressure by delaying IVC. Thus, this strategy allowed for an earlier combustion phasing to minimize fuel efficiency penalty and soot emissions while maintaining lower NOx level benefit achieved by EGR. Additionally, the combined strategy achieved the biggest benefit in NOx abatement, decreasing the NOx levels of the baseline case by $57 \%$ and the fuel efficiency by $1.6 \%$ while maintaining soot emissions below Euro VI limit of $0.01 \mathrm{~g} / \mathrm{kWh}$.

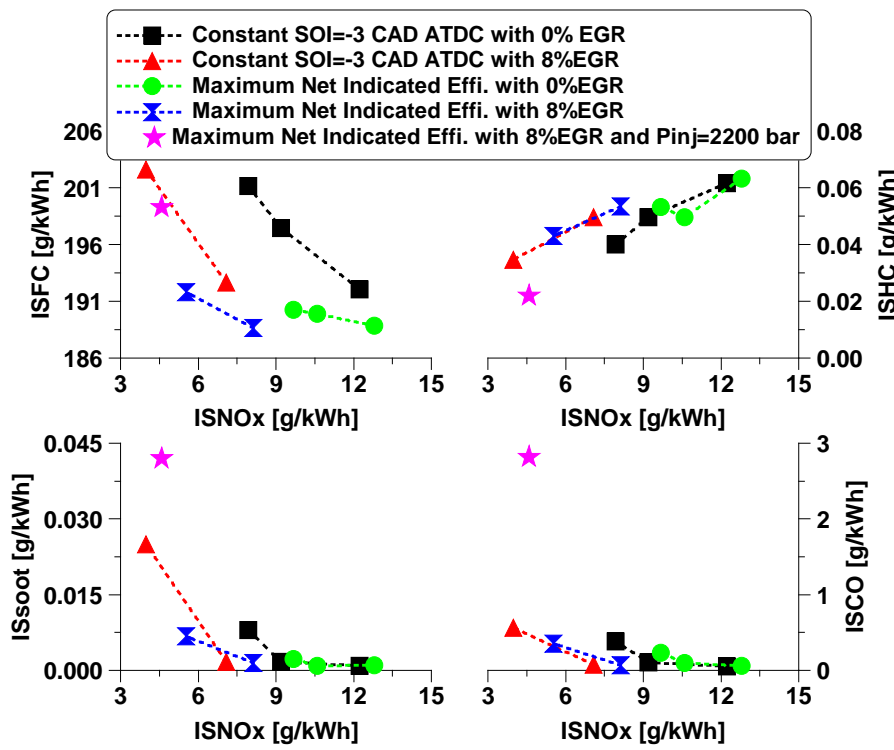

Figure 9. The effect of Miller cycle and EGR on NOx, ISFC and ISssot tradeoffs.

\section{Analysis of cost-benefit and overall emissions at the maximum net indicated efficiency}

In this study, an urea SCR system is assumed for NOx control in order to estimate the total cost of ownership. Since the TCO is determined by several aspects, such as diesel fuel and aqueous urea solution consumptions, fuel prices, engine efficiency and engine-out NOx emissions, the TCO might not be the lowest with a high engine efficiency setup. Therefore, an analysis of cost-benefit and overall emissions was carried out at the optimum net indicated efficiency, in order to determine the best trade-off between the engine efficiency and the engine-out NOx emissions for minimizing the total fluid cost and thus the TCO.

Since the aqueous urea solution used in the SCR system was estimated based on the engine-out NOx emissions and the Euro VI limit of $0.40 \mathrm{~g} / \mathrm{kWh}$, an improvement in engine-out NOx emissions will allows for the urea usage savings. For better understanding the effectiveness of Miller cycle and EGR strategies compared to the baseline, the aqueous urea solution consumptions (murea), based on the engine-out NOx emissions to meet the Euro VI NOx limit, was calculated as

$$
\dot{\mathrm{m}}_{\text {urea }}=0.01\left(\mathrm{NOX} \text { Engine-out }-\mathrm{NOX} \mathrm{x}_{\text {EuroVI }}\right) \dot{\mathrm{m}}_{\text {diesel }}
$$

where murea is estimated by assuming $1 \%$ of the diesel equivalent fuel flow per $\mathrm{g} / \mathrm{kWh}$ NOx reductions [4,27-29]. As the relative prices between diesel fuel and urea are different in different countries and regions, the price and property of urea was simulated to be the same as diesel fuel in this study $[4,28]$. By adding the diesel fuel consumption to the estimated urea usage allowed for the calculation of total fluid consumption and the corrected net indicated efficiency (Net Indicated Effi.corr.), which were defined as

$$
\dot{\mathrm{m}}_{\text {total }}=\dot{\mathrm{m}}_{\text {urea }}+\dot{\mathrm{m}}_{\text {diesel }}
$$

Page 7 of 19 
and

$$
\text { Net Indicated Eff. } \text { corr. }=\frac{P_{i}}{\left(\dot{\mathrm{m}}_{\text {diesel }}+\dot{\mathrm{m}}_{\text {urea }}\right) \mathrm{LHV}_{\text {diesel }}}
$$

where $\mathrm{P}_{\mathrm{i}}$ is the net indicated power and the $\mathrm{LHV}_{\text {diesel }}$ is the lower heating value of diesel fuel.

Figure 10 shows the diesel fuel flow rate and the required urea consumption to meet Euro VI NOx limit for each case. Both EGR and Miller cycle strategies increased the diesel fuel flow rate as explained previously. Advancing combustion phasing in terms of the most efficient cases resulted in significantly lower diesel fuel flow rate compared to those at a constant SOI. With the use of EGR, the required urea flow rate dropped clearly due to decreased engine-out NOx emissions.

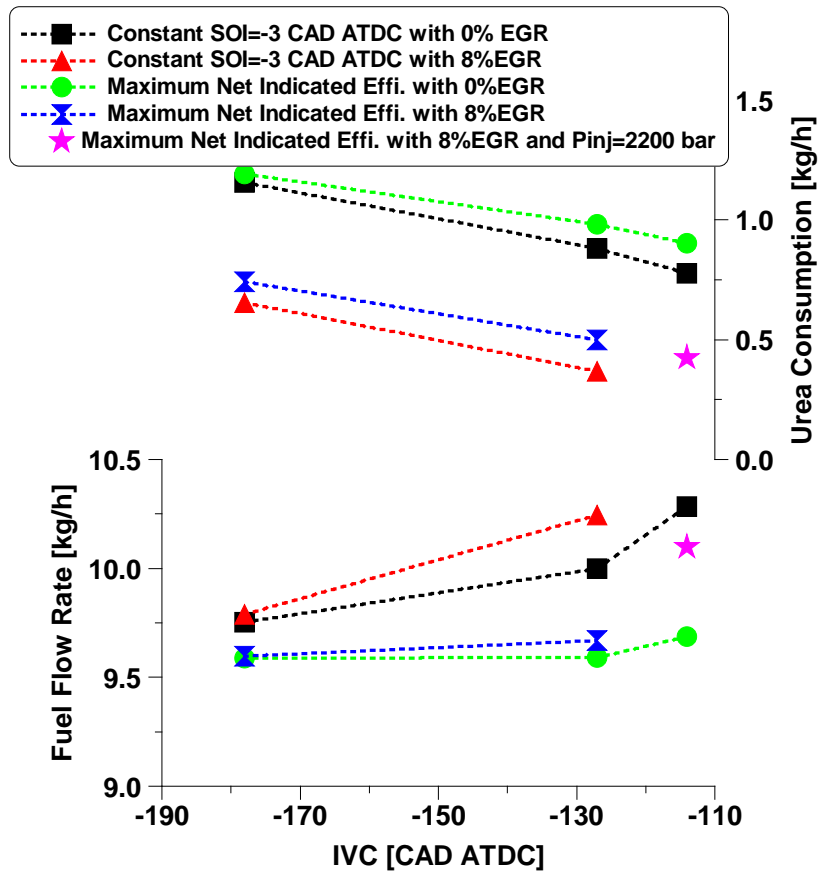

Figure 10. Diesel fuel flow rate and the required urea flow rate for various strategies.

Figure 11 shows an overall comparison of ISNOx, ISFC, the required urea consumption in the SCR system, as well as the total fluid consumption and the resultant Net Indicated Effi.corr. The analysis was carried out with the maximum engine efficiencies in various strategies. The resulting values of IVC at -178 CAD ATDC with no EGR was used as the reference value. As for the case of IVC at -114 CAD ATDC with 8\%EGR, a higher injection pressure of 2200 bar was applied to avoid excessive smoke and lower engine efficiency.

The baseline IVC with no EGR led to the lowest Net Indicated Effi.corr., although the highest fuel efficiency was achieved. This was a result of the higher urea consumption required in the SCR system due to the higher engine-out NOx emissions, resulting in an increase of the total fluid consumption. Both Miller cycle and EGR strategies showed higher Net Indicated Effi.corr. than the baseline mainly attributed to the lower total fluid consumption despite a small fuel efficiency penalty.

It can be seen that the highest Net Indicated Effi.corr. of $41.6 \%$ was achieved when the IVC was delayed to -127 CAD ATDC with $8 \%$ EGR, owing to the significantly lower engine-out NOx emissions. Although the highest reduction of NOx emissions by $64 \%$ was

Page 8 of 19 obtained when delaying IVC to -114 CAD ATDC with 8\%EGR, the fuel efficiency noticeably reduced, leading to lower Net Indicated Effi.corr. than IVC at -127 CAD ATDC with 8\%EGR. Overall, among these strategies the Miller cycle with IVC at -127 CAD ATDC combined with $8 \%$ EGR showed the optimum trade-off between engine-out NOx emissions and engine efficiency, reducing the total fluid consumption by 5.8\% and increasing the Net Indicated Effi.corr. by $5.3 \%$ compared to reference case.

Therefore, the combination of Miller cycle and external cooled EGR strategy at a fixed boost pressure shows a great potential to reduce engine-out NOx emissions with little impact on fuel efficiency, while achieving the lowest total fluid consumption and consequently the highest Net Indicated Effi.corr. The results also demonstrate the optimum balance existed between in-cylinder NOx control and aftertreatment NOx control and it is determined by the total fluid consumption and the Net Indicated Effi.corr.

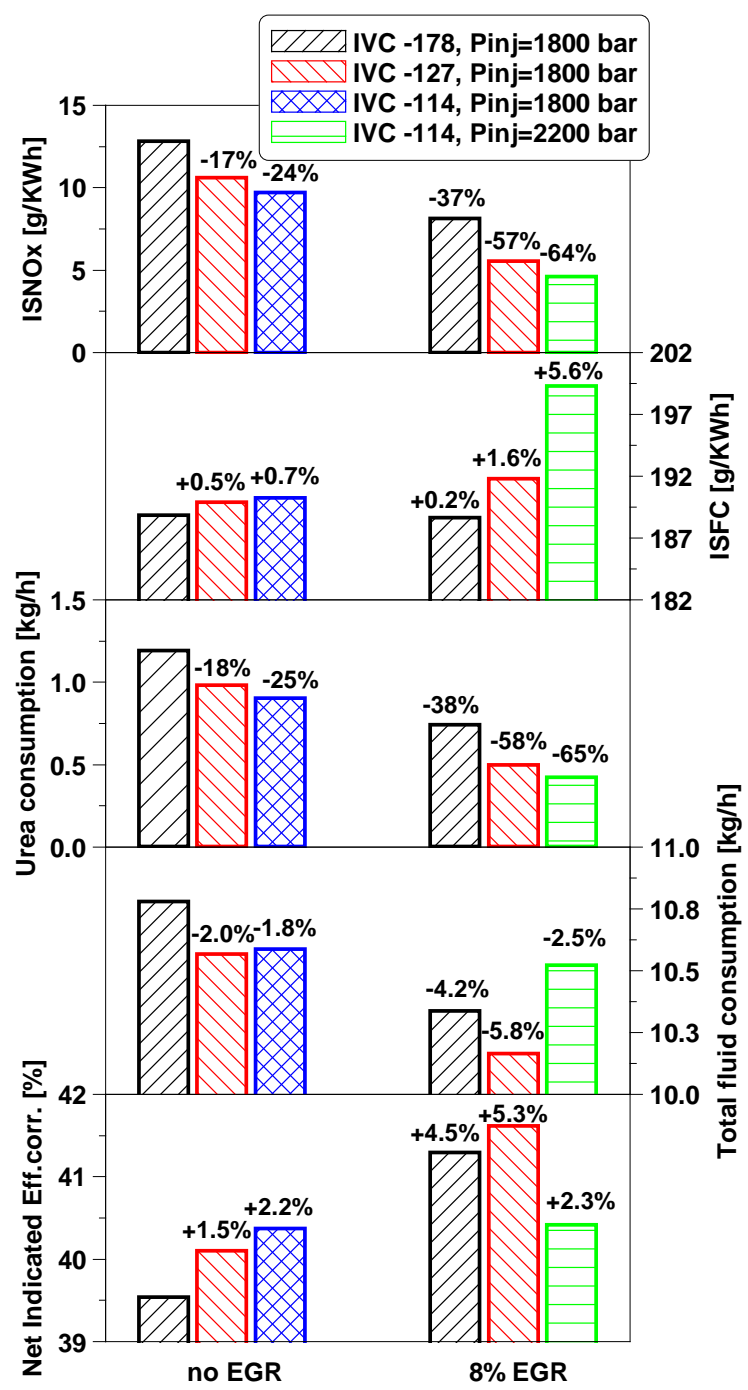

Figure 11. Overall evaluation of NOx reduction potential for various combustion strategies.

\section{Conclusions}

In this study, an experimental investigation was carried out to explore the NOx reduction potential of Miller cycle and EGR at a full load 
operation of 24 bar IMEP at 1250rpm with a constant intake pressure of 3 bar. The work was performed on a single cylinder heavy-duty diesel engine with a common rail fuel injection system. The engine was equipped with a VVA system on the intake camshaft and a highpressure loop cooled EGR for the application of Miller cycle and EGR strategies. Diesel SOIs were swept and optimized up against the peak in-cylinder pressure limit to achieve the maximum net indicated efficiency in various strategies. Finally, an analysis of cost-benefit and engine-out emissions was conducted at the optimum net indicated efficiency cases. The main findings can be summarized as follows:

1. The application of Miller cycle via late IVCs lowered the compression pressure and temperatures and hence the flame temperatures, so that the peak in-cylinder pressure and NOx emissions could be reduced simultaneously.

2. The use of EGR was more effective in minimizing NOx emissions than the Miller cycle strategy while maintaining a similar engine efficiency to that of baseline case. This was a result of lower average and flame combustion temperatures as well as oxygen concentration from EGR, which are critical to the NOx formation and the lower combustion temperature is beneficial to the heat loss reduction.

3. For a given intake boost pressure, the greater effect on reducing peak in-cylinder pressure by Miller cycle combined with the higher NOx reduction potential of EGR produced the best NOx-ISFC and NOx-soot trade-offs by optimized SOIs.

4. The Miller cycle with IVC -127 combined with 8\%EGR was effective in reducing engine out NOx emissions by approximately $57 \%$ with negligible impact on the fuel efficiency compared to the baseline IVC with no EGR, while maintaining the soot emissions below Euro VI limit. This improvement notably minimized the required urea consumption in the SCR system and thus achieved the highest corrected net indicated efficiency.

5. There is an optimum balance between in-cylinder NOx control and aftertreatment NOx control to obtain the lowest total cost of ownership, which could be achieved by the optimization of Miller cycle and external cooled EGR strategies. A reduction in the total fluid consumption by $5.8 \%$ was achieved in the full load operation of 24 bar IMEP at 1250rpm with a constant intake pressure of 3 bar.

\section{References}

1. Heywood J.B, "Internal Combustion Engine," ISBN $007028637 X, 1988$.

2. Federal legislation, "Final Rule for Greenhouse Gas Emissions and Fuel Efficiency Standards for Medium- and Heavy-Duty Engines and Vehicles - Phase 2," 81(206):73478-74274, 2011, doi:http://www.nhtsa.gov/Laws+\&+Regulations/CAFE++Fuel+Economy/Fuel+economy+and+environment+label.

3. Reitz, R.D., "Directions in internal combustion engine research," Combust. Flame 160(1):1-8, 2013, doi:10.1016/j.combustflame.2012.11.002.

4. Charlton, S., Dollmeyer, T., and Grana, T., "Meeting the US Heavy-Duty EPA 2010 Standards and Providing Increased Value for the Customer," SAE Int. J. Commer. Veh. 3(1):101-
110, 2010, doi:10.4271/2010-01-1934.

5. Hasegawa, R. and Yanagihara, H., "HCCl Combustion in DI Diesel Engine," 2003, doi:10.4271/2003-01-0745.

6. Doosje, E., Willems, F., Baert, R., and Dijk, M. Van, "Experimental Study into a Hybrid $\mathrm{PCCl} / \mathrm{Cl}$ Concept for Next-Generation Heavy-Duty Diesel Engines," SAE Tech. Pap. 2012-01-1114 (x), 2012, doi:10.4271/2012-01-1114.

7. Asad, U. and Zheng, M., "Exhaust gas recirculation for advanced diesel combustion cycles," Appl. Energy 123:242252, 2014, doi:10.1016/j.apenergy.2014.02.073.

8. Benajes, J., Molina, S., Novella, R., and Belarte, E., "Evaluation of massive exhaust gas recirculation and Miller cycle strategies for mixing-controlled low temperature combustion in a heavy duty diesel engine," Energy 71:355366, 2014, doi:10.1016/j.energy.2014.04.083.

9. Stebler, H., Weisser, G., Hōrler, H.-U., and Boulouchos, K., "Reduction of NOx Emissions of D. I. Diesel Engines by Application of the Miller-System: An Experimental and Numerical Investigation," SAE Technical Paper, 1996, doi:10.4271/960844.

10. Codan, E. and Vlaskos, I., "Turbocharging medium speed diesel engines with extreme Miller timing," Proc. 9th Turbocharging Conf. Dresden, Ger. Sept. 23-24, 2004.

11. Schutting, E., Neureiter, A., Fuchs, C., Schatzberger, T., and Klell, M., "Miller- and Atkinson-Cycle on a Turbocharged Diesel Engine Authors :," 68, 2007.

12. Gonca, G., Sahin, B., Parlak, A., Ayhan, V., Cesur, I., and Koksal, S., "Application of the Miller cycle and turbo charging into a diesel engine to improve performance and decrease NO emissions," Energy 93:795-800, 2015, doi:10.1016/j.energy.2015.08.032.

13. Rinaldini, C.A., Mattarelli, E., and Golovitchev, V.I., "Potential of the Miller cycle on a HSDI diesel automotive engine," Appl. Energy 112(x):102-119, 2013, doi:10.1016/j.apenergy.2013.05.056.

14. Wang, Y., Zeng, S., Huang, J., He, Y., Huang, X., Lin, L., and Li, S., "Experimental Investigation of Applying Miller Cycle to Reduce $\mathrm{NO}_{\mathrm{x}}$ Emission From Diesel Engine," Proc. Inst. Mech. Eng. Part A J. Power Energy 219(8):631-638, 2006, doi:10.1243/095765005X31289.

15. Benajes, J., Molina, S., Martín, J., and Novella, R., "Effect of advancing the closing angle of the intake valves on diffusion-controlled combustion in a HD diesel engine," Appl. Therm. Eng. 29(10):1947-1954, 2009, doi:10.1016/j.applthermaleng.2008.09.014.

16. Zhang, Y., Wang, Z., Bai, H., Guo, C., and Li, Y., "The Reduction of Mechanical and Thermal Loads in a HighSpeed HD Diesel Engine Using Miller Cycle with Late Intake Valve Closing," SAE Tech. Pap., 2017, doi:10.4271/2017-010637.

17. Kim, J. and Bae, C., "An investigation on the effects of late intake valve closing and exhaust gas recirculation in a

Page 9 of 19 
single-cylinder research diesel engine in the low-load condition," Proc. Inst. Mech. Eng. Part D J. Automob. Eng. 230(6):771-787, 2016, doi:10.1177/0954407015595149.

18. Sjöblom, J., "Combined Effects of Late IVC and EGR on Lowload Diesel Combustion," SAE Tech. Pap. 1(2878), 2014, doi:10.4271/2014-01-2878.

19. Verschaeren, R., Schaepdryver, W., Serruys, T., Bastiaen, M., Vervaeke, L., and Verhelst, S., "Experimental study of NOx reduction on a medium speed heavy duty diesel engine by the application of EGR (exhaust gas recirculation) and Miller timing," Energy 76(x):614-621, 2014, doi:10.1016/j.energy.2014.08.059.

20. Kovács, D. and Eilts, P., "Potentials of the Miller Cycle on HD Diesel Engines Regarding Performance Increase and Reduction of Emissions," SAE Tech. Pap., 2015, doi:10.4271/2015-24-2440.

21. Regulation No 49- uniform provisions concerning the measures to be taken against the emission of gaseous and particulate pollutants from compression-ignition engines and positive ignition engines for use in vehicles. Off J Eur Union, 2013.

22. AVL., "AVL 415SE Smoke Meter," Prod. Guid. Graz, Austria;, 2013.

23. Stricker, K., Kocher, L., Koeberlein, E., Alstine, D. Van, and Shaver, G.M., "Estimation of effective compression ratio for engines utilizing flexible intake valve actuation," Proc. Inst. Mech. Eng. Part D J. Automob. Eng. 226(8):1001-1015, 2012, doi:10.1177/0954407012438024.

24. Garg, A., Magee, M., Ding, C., Roberts, L., Shaver, G., Koeberlein, E., Shute, R., Koeberlein, D., McCarthy, J., and Nielsen, D., "Fuel-efficient exhaust thermal management using cylinder throttling via intake valve closing timing modulation," Proc. Inst. Mech. Eng. Part D J. Automob. Eng. 230(4):470-478, 2016, doi:10.1177/0954407015586896.

25. Ladommatos, N., Abdelhalim, S.M., Zhao, H., and Hu, Z., "The Dilution, Chemical , and Thermal Effects of Exhaust Gas Recirculation on Diesel Engine Emissions - Part 4 : Effects of Carbon Dioxide and Water Vapour," (412), 1997.

26. Guan, W., Pedrozo, V., Zhao, H., Ban, Z., and Lin, T., "Investigation of EGR and Miller Cycle for NOx Emissions and Exhaust Temperature Control of a Heavy-Duty Diesel Engine," SAE Tech. Pap., 2017, doi:10.4271/2017-01-2227.

27. Pedrozo, V.B., May, I., and Zhao, H., "Exploring the mid-load potential of ethanol-diesel dual-fuel combustion with and without EGR," Appl. Energy 193:263-275, 2017, doi:10.1016/j.apenergy.2017.02.043.

28. Hanson, R., Ickes, A., and Wallner, T., "Comparison of RCCl Operation with and without EGR over the Full Operating Map of a Heavy-Duty Diesel Engine," SAE Tech. Pap. (x), 2016, doi:10.4271/2016-01-0794.

29. Johnson, T. V, "Diesel Emissions in Review," SAE Int. J. Engines 4(1):143-157, 2011, doi:10.4271/2011-01-0304.

\section{Contact information}

Wei Guan

Wei.guan@brunel.ac.uk

gwei916@163.com

Centre for Advanced Powertrain and Fuels Research

College of Engineering, Design and Physical Sciences

Brunel University London

Kingston Lane

Uxbridge

Middlesex UB8 3PH

United Kingdom

\section{Acknowledgments}

The first author, Mr W Guan, would like to acknowledge the Guangxi Yuchai Machinery Company for supporting his PhD study supervised by Prof. Zhao at Brunel University London.

\section{Definitions/Abbreviations}

$\begin{array}{ll}\text { ATDC } & \text { After Firing Top Dead Center. } \\ \text { CA50 } & \text { Crank Angle of 50\% Cumulative Heat Release } \\ \text { CA10-CA90 } & \text { Combustion Duration. } \\ \text { CAD } & \text { Crank Angle Degree. } \\ \text { CO } & \text { Carbon Monoxide. } \\ \text { CO2 } & \text { Carbon Dioxide. } \\ \text { COV_IMEP } & \text { Coefficient of Variation of IMEP } \\ \text { (CO2\%)intake } & \text { Carbon Dioxide Concentration of Intake } \\ \text { (CO2\%)exhaust } & \text { Carbon Dioxide Concentration of Exhaust } \\ \text { ECR } & \text { Effective Compression Ratio. } \\ \text { ECU } & \text { Electronic Control Unit. } \\ \text { EGR } & \text { Exhaust Gas Recirculation. } \\ \text { EGT } & \text { Exhaust Gas Temperature. } \\ \text { HCCI } & \text { Homogenous Charge Compression Ignition } \\ \text { PCCI } & \text { Premixed Charge Compression Ignition } \\ \text { HRR } & \text { Heat Release Rate. } \\ \text { HC } & \text { Hydrocarbons. } \\ \text { IMEP } & \text { Indicated Mean Effective Pressure. } \\ \text { IVC } & \text { Intake Valve Closing. } \\ \text { IVO } & \text { Intake Valve Opening. } \\ \text { ISFC } & \text { Net Indicated Specific Fuel Consumption. } \\ \text { ISSoot } & \text { Net Indicated Specific Emissions of Soot. } \\ \text { ISNOx } & \text { Net Indicated Specific Emissions of NOx. } \\ \text { ISCO } & \text { Net Indicated Specific Emissions of CO. } \\ \text { ISHC } & \text { Net Indicated Specific Emissions of Unburned HC. } \\ \text { LTC } & \text { Low Temperature Combustion } \\ \text { MFB } & \text { Mass Fraction Burned } \\ \text { NOx } & \text { Nitrogen Oxides. } \\ \text { Pmax } & \text { Maximum In-cylinder Pressure } \\ \text { Pinj } & \text { Injection Pressure } \\ \text { SOI } & \text { Start of Injection } \\ \text { SCR } & \text { Selective Catalytic Reduction. } \\ \text { TDC } & \text { Firing Top Dead Centre. } \\ \text { TCO } & \text { Total Cost of Ownership } \\ \text { VVA } & \text { Variable Valve Actuation } \\ \text { WHSC } & \text { World Harmonized Stationary Cycle. } \\ & \end{array}$

Page 10 of 19 


\section{Appendix A. Test cell measurement devices}

\begin{tabular}{|c|c|c|c|c|}
\hline Variable & Device & Manufacturer & Measurement range & Linearity/Accuracy \\
\hline Speed & $\begin{array}{c}\text { AG } 150 \\
\text { Dynamometer }\end{array}$ & Froude Hofmann & 0-8000 rpm & $\pm 1 \mathrm{rpm}$ \\
\hline Torque & $\begin{array}{c}\text { AG } 150 \\
\text { Dynamometer }\end{array}$ & Froude Hofmann & $0-500 \mathrm{Nm}$ & $\pm 0.25 \%$ of FS \\
\hline $\begin{array}{l}\text { Diesel flow rate } \\
\text { (supply) }\end{array}$ & $\begin{array}{l}\text { Proline promass } \\
\text { 83A DN01 }\end{array}$ & Endress+Hauser & $0-20 \mathrm{~kg} / \mathrm{h}$ & $\pm 0.10 \%$ of reading \\
\hline $\begin{array}{l}\text { Diesel flow rate } \\
\text { (return) }\end{array}$ & $\begin{array}{l}\text { Proline promass } \\
\text { 83A DN02 }\end{array}$ & Endress+Hauser & $0-100 \mathrm{~kg} / \mathrm{h}$ & $\pm 0.10 \%$ of reading \\
\hline $\begin{array}{l}\text { Intake air mass flow } \\
\text { rate }\end{array}$ & Proline t-mass $65 \mathrm{~F}$ & Endress+Hauser & 0-910 kg/h & $\pm 1.5 \%$ of reading \\
\hline In-cylinder pressure & $\begin{array}{c}\text { Piezoelectric } \\
\text { pressure sensor } \\
\text { Type } 6125 \mathrm{C}\end{array}$ & Kistler & 0-300 bar & $\leq \pm 0.4 \%$ of $F S$ \\
\hline $\begin{array}{c}\text { Intake and exhaust } \\
\text { pressures }\end{array}$ & $\begin{array}{l}\text { Piezoresistive } \\
\text { pressure sensor } \\
\text { Type 4049A }\end{array}$ & Kistler & 0-10 bar & $\leq \pm 0.5 \%$ of $\mathrm{FS}$ \\
\hline Oil pressure & $\begin{array}{l}\text { Pressure transducer } \\
\text { UNIK } 5000\end{array}$ & GE & 0-10 bar & $< \pm 0.2 \%$ FS \\
\hline Temperature & $\begin{array}{c}\text { Thermocouple } \mathrm{K} \\
\text { Type }\end{array}$ & RS & 233-1473K & $\leq \pm 2.5 \mathrm{~K}$ \\
\hline Intake valve lift & $\begin{array}{c}\text { S-DVRT-24 } \\
\text { Displacement } \\
\text { Sensor }\end{array}$ & LORD MicroStrain & $0-24 \mathrm{~mm}$ & $\begin{array}{l} \pm 1.0 \% \text { of reading using } \\
\text { straight line }\end{array}$ \\
\hline Smoke number & 415SE & AVL & 0-10 FSN & - \\
\hline $\begin{array}{l}\text { Fuel injector current } \\
\text { signal }\end{array}$ & Current Probe PR30 & LEM & $0-20 \mathrm{~A}$ & $\pm 2 \mathrm{~mA}$ \\
\hline
\end{tabular}


Appendix B. Smoke number

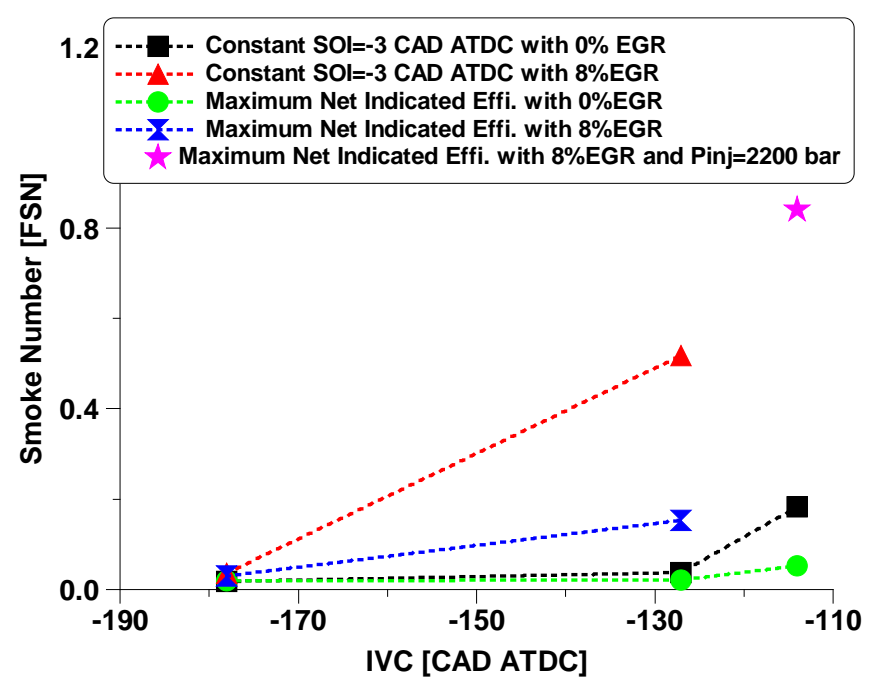

Page 12 of 19 
Dear Organizers and Reviewers,

Thank you for your kind comments and suggestions to the manuscript. We have modified the manuscript accordingly, and detailed corrections are listed below point by point. The black parts are the reviewers' comments, and the blue parts are our responses. All the revisions are highlighted in the manuscript using the red text.

We look forward to your positive response.

Sincerely,

Wei Guan

Brunel University London

Reviewer \#: 215712

1. The reported soot values are quite low. Can the authors report the FSN values as well? Have the authors performed verification tests or calibrations on the smoke measurement system? Although this doesn't change the bulk of the paper discussions, it will impact the NOx-soot tradeoff.

Thanks for the kind suggestion. A daily check was taken every day before starting formal testing. We have added the FSN values in the Appendix B while the details of smoke measurement system can be seen in the Appendix A.

2. Some of the data points reported had quite high levels of NOx. It seems to the reviewer that the high levels of urea consumption ( $\sim 10 \%$ of fuel flow) would be undesirable and the high level of NOx aftertreatment effectiveness ( 96\%) required would be very demanding. Thus the fuel and urea is not exactly equivalent in terms of practical economy. The reviewer believes the authors should address this aspect briefly in the discussion.

The combined use Miller cycle and EGR at full load required enough high intake boost pressure and rail pressure to avoid excessive smoke and dramatically lower indicated efficiency. Most importantly, the used ECU in the test cell would stop injection once the limitation of maximum injection duration is reached at full load conditions, which can be avoided using higher intake boost pressure and rail pressure. Therefore, the high intake boost pressure and rail pressure were employed for each case in order to ensure a fair comparison, which resulted in much higher NOx levels at the baseline operation.

Additonal points

The reviewer suggests that the authors use the article “the” before the term Miller cycle in many of the author's usages.

Thanks, they have been revised.

Abstract, paragraph 3, “... decreasing the NOx levels of baseline case...” of is the wrong wording. The authors mean decreased X amount compared to the baseline case.

This has been rewritten as "decreasing the NOx levels by $57 \%$ and the fuel efficiency by $1.6 \%$ compared to the baseline case”.

Page 4, paragraph 1, “oil temperatures were kept within at (sic)...”

Thanks, this has been revised.

Page 4, paragraph 4, “... which could partly eliminated (sic) the adverse.... In comparison, the....” This part is confusing and should be rewritten.

This has been rewritten on Page 4 as “...due to the replacement of the fresh air with recirculated exhaust gas instead of reducing the in-cylinder air mass in the Miller cycle strategy. Overall, the combined strategy of Miller cycle and EGR achieved the highest reduction in the peak in-cylinder pressure...”

Page 5, paragraph 3, "as a result of the reduced in-cylinder air density...” Can the authors explain what they mean with respect to the reduce density impacting the mixing process?

This has been revised as "as a result of the reduced in-cylinder charge and the dilution effect, both Miller cycle and EGR strategies reduced the incylinder availability oxygen during the mixing-controlled combustion stage”.

Page 13 of 19 
Page 6, paragraph 1, “The use of EGR presented a little impact on the.... However, the addition of EGR showed clear impact...” These two statements contradict each other.

Thanks, this sentence has been rewritten as "Besides, the higher lambda value at baseline IVC with EGR was also the primary reason for the insignificant effect on EGT. However, the addition of EGR showed clear impact on exhaust gas temperatures when operating with Miller cycle due to the much lower lambda value with a delayed IVC timing”.

Page 7, paragraph 1, “A further reduction in NOx emissions by 45\%...” The description is wrong. Further must refer to the second reference point, not the original. Example: The number four is $50 \%$ less than eight. A further reduction by $50 \%$ would be the number two.

It has been modified by "A higher reduction in NOx emission by $45 \%$...”

References 16, 20, 21, 22, are incorrect in terms of formatting or missing information.

Thanks, all the mentioned references have been modified.

Reviewer \#: 215713

1. It's not clear why the authors chose -127 and -114CAD ATDC as the Miller Cycle IVCs. Is there some background study that was performed to determine these timings? Could there be a timing which can perform better than -127 ?

Thanks for this kind suggestion. The reason for choosing -127 and -114 CAD ATDC is because, when delayed IVC timing to -145 CAD ATDC, as shown in the Figure below, there was less impact on the in-cylinder air mass and thus the emissions and efficiency mainly due to the inherently high flow resistance across the intake valves and inertia of the gas in the intake port as well as the dynamic charging effect. However, a later IVC timing such as the tested IVC-127 CAD ATDC, will then cause apparently backflow into the intake manifold as a result of the upward piston motion pushing the mass out of the cylinder before the valve closes. But the lambda decreased significantly as delayed IVC timing further to - 114 CAD ATDC, especially when combined with EGR, the lambda value dropped even below 1.12, which led to excessive smoke and lower efficiency. But we not sure if there be a timing which can perform better than -127 since the interval between -127 and -114 CAD ATDC is relatively small.

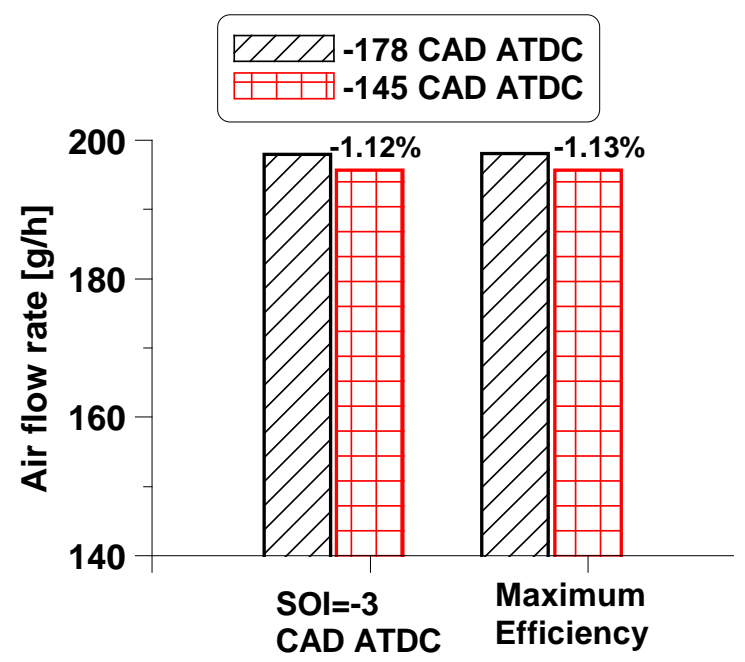

2. Pg 4, 2nd column: Figure 4 only shows -127 timing though the authors describe that both -127 and -114 are shown in the figure.

The curves of IVC-114 have been added in Figure 3 and Figure 5.

3. Figure 5: It would be useful to the reader if the efficiencies are incorporated in the figure in some way.

Thanks for the kind suggestion. The selected calibrations for maximum efficiency have been added in Figure 4. It can be seen that the injection timings of all cases have been swept up against the peak in-cylinder pressure of 180 bar where the maximum efficiencies were achieved.

4. The section on combustion characteristics describes results for optimum indicated efficiency though the values are not mentioned until the next section. The authors can consider moving the engine performance section before the combustion characteristics.

Page 14 of 19

7/20/2015 
The selected calibrations for maximum indicated efficiency have been added in Figure 4.

5. Typos/Language errors - Page 5, Col 1, Para 3, Line 2: "the both"

Page 6, Col 2, Para 3, Line 4: "and accompany with"

Thanks, both have been revised.

\section{Reviewer \#: 215714}

This paper discusses the emission reduction and efficiency improvement with the combination of Miller cycle and EGR under a high load engine operating conditions.

A few comments as follows:

1. There are some typos and grammar mistakes. To list a few as examples:

Page 4: The "ECR" equation should be equation number "(2)" instead of "(1)"

Page 4: "All valve events was..." should be "All valve events were..."

Page 4: "while the intake valve timings were delayed from -178 CAD ATDC...", should be "while the intake valve closing timings were delayed from -178 CAD ATDC..."

Thanks, these mistakes have been modified in the corresponding pages.

Page 4: "Figure 4 shows the in-cylinder pressure and heat release rate for both the baseline (-178 CAD) and Miller cycle (IVC-127 and IVC -114)...", while in the figure there are no curves showing the results for IVC -114.

The results for IVC-114 have been added in Figure 3 and Figure 5.

2. Page 6 first paragraph, "However, the addition of EGR showed clear impact on exhaust gas temperatures due to the much lower lambda value.", while in the previous sentence the author said "EGR presented a little impact on the exhaust gas temperature when operating with the baseline IVC". It is confusing. Did the author want to express that the effect of EGR on exhaust gas temperature was more significant in Miller cycles?

Yes, the effect of EGR with Miller cycles on exhaust gas temperature is more significant than that with the baseline IVC due to the much lower lambda value. This has been rewritten on Page 6.

3. The authors used EGR ratio of $8 \%$ for all the EGR tests. Have other EGR ratios been tested? What would be the impact of different EGR ratios in the application of Miller cycle?

The addition of EGR ratio at full load was limited by the supplied intake boost pressure and the used EGR ratio of $8 \%$ in this study was nearly the maximum at the supplied intake boost pressure of 3 bar. As for the impact of different EGR ratios, we didn't sweep the EGR rate because this study was aim to analyze the effect of Miller cycle on engine combustion, emissions and efficiency with and without EGR. Moreover, the range for EGR sweeping is much small.

4. Could you add the information of the injection timing for the optimized efficiency cases?

The injection calibration for the maximum efficiency has been added in Figure 4 on Page 5.

5. In the analysis of cost benefit the author considered the total cost of diesel fuel and urea solution, which is good as the efficiency of the whole system is more important when the TCO is considered. The author assumed the price of urea and diesel was the same and calculated the net indicated efficiency based on this assumption. Could you add a figure indicating separately the fuel consumption and urea consumption in each case?

Thanks for the kind suggestion. We have added this in Figure 10 on Page 8.

Page 15 of 19

$7 / 20 / 2015$ 
Reviewer \#: 215728

Abstract:

1. Combine 2nd and 1st paragraphs and add a transition between the two

The first two paragraphs have been combined and a transition has been added.

2. Combustion temperatures decrease, NOx decreases and CO emissions increase - this is a common tradeoff; however, you should not state that you can reduce $\mathrm{CO}$ emissions by optimizing injection timing....this will lead to an increase in NOx emissions, counteracting what you just accomplished. Simply state the findings in your abstract.

Thanks, this sentence has been rewritten as "carbon monoxide emissions maintained at low levels except for the combination of IVC at -114 CAD ATDC and 8\%EGR”.

Introduction:

\section{Maintain consistency on "NOx"}

Thanks. It has been modified.

4. Work on transitioning between paragraphs to tell a more effective story

Some modifications have been added in the Introduction for a better transition.

\section{5. "hydrocarbon"}

This has been corrected.

6. "massive soot reduction" - remove relative words like "massive" from the paper. They are subjective and mean different things to different people. Stick to the numbers and let the readers make their own determination

Thanks for the kind suggestion. These have been modified.

7. Nice literature review

Thanks.

8. "further in the expansion stroke" - grammar can be improved

This has been revised.

9. Kovacs [20] - significant improvement in NOx - soot tradeoff; what was this? Did they find higher or lower NOx emissions? I would like to see a little more discussion of this reference while framing it in consideration with the other findings.

In the combination of Miller cycle with higher boost pressure at constant CA50 and NOx emission by adjusting the start of injection and EGR rate respectively, soot and $\mathrm{CO}$ emissions were significantly reduced, and thus a significant improvement in the trade-offs between

NOx, soot and CO. The cited reference [20] has been rewritten on Page 2.

10. OK, what I get out of your literature review: Miller cycle and EGR can help lower NOx emissions (stated) while potentially lowering the fuel conversion efficiency (stated). Moreover, it appears that $\mathrm{CO}, \mathrm{HC}$, and PM emissions may increase although a couple researchers found reduced soot [13] and HC [19] emissions. I would add something to the effect of my second sentence to provide a true picture in the introduction before discussing the total cost of ownership.

Thanks for the kind suggestion.

Experimental Setup:

11. Need to include the model numbers \& manufacturers of the equipment used. For example, the eddy current dynamometer, supercharger, displacement sensor, thermal mass flow meter, etc. All pertinent information should be provided (along with measurement accuracy) so that others could reproduce your results if they wanted to.

Page 16 of 19 
The specifications of measurement devices have been added in the Appendix A.

\section{How was the start of combustion determined?}

The start of combustion was set to $0.3 \%$ mass fraction burned (MFB) point of the average cycle.

\section{Subscript needed: $\mathrm{CO} 2$}

It has been revised.

Methodology

\section{Why only two EGR percentages? That is not enough to describe a trend.}

The reason we didn't swept the EGR rates is because the aim of this study is to analyze the effect of Miller cycle on engine combustion, emissions and efficiency under the conditions of with and without EGR. Besides, the EGR ratio at full load was limited to around 8\% with the supplied intake boost pressure of 3 bar when combining with Miller cycle. Thus the available range foe EGR sweeping is much small.

15. You cannot just randomly increase the injection pressure for one test because that skews all outcomes as the fuel injection process is now different. You need to remove this test; although this creates a problem for your analysis since you would only have one -IVC and $8 \%$ EGR.

Thanks, the test point of IVC-114 with 8\%EGR using higher injection pressure of 2200 bar has been separated from those test points operating at a constant injection pressure of 1800 bar, as shown in Table 2 and all Figures.

\section{I assume you tested under steady state conditions - how did you determine steady-state?}

Yes, it is. The pressure rise rate and the coefficient of variation of IMEP were limited to 20 bar/CAD and 3\% respectively during the study, which have been added on Page 4.

17. Figure 3 - these are data points; hence, there should not be a line connecting them, and I do not believe that this graph is needed since the same information is in Table 2

Thanks for the kind suggestion, this Figure has been removed.

Results and discussion

18. Interestingly, the IVC-114 + 8\% EGR in-cylinder plots are not provided (the point of increasing the fuel injection pressure). You should show all in-cylinder plots and this will help us (reviewers) note whether or not this data point is valid to include (I am betting it is not and the in-cylinder pressure will show this). Note, your text indicates that it is in Figure 4.

In-cylinder plots for IVC-114 have been added in Figure 3 and Figure 5.

19. I would like to see more of a discussion around Figure 5 and how EGR does slow the combustion process and can result in a more advanced timing to maximize thermal efficiency. You state there is "little difference" - you should discuss why there is any difference.

Thanks, more discussion about Figure 5 has been added and the analysis section was rewritten as "The dilution and higher heat capacity introduced by EGR slower the combustion process and slightly reduced the in-cylinder pressure, as depicted in Figure 3, allowing for a more advanced timing to maximize indicated efficiency. However, the difference between the optimized (most advanced) diesel injection timing with and without EGR of the baseline IVC was less significant than the Miller cycle operation”.

20. Experimental plots - remove lines between data and provide error bars. Experimental data are distinct values with error; hence, you can use trend lines to highlight trends, but drawing a line between two data points infers a linear trend and that may not be the case.

Thanks for the good suggestion, all lines between data have been changed from solid lines to dash lines in order to avoid misleading.

21. Why did you jump from -178 to -127 ? That is a significant difference, it would have been best to test smaller increments in IVC.

As shown in the Figure below, when delayed IVC to -145 CAD ATDC, there was less impact on the in-cylinder air mass and thus the emissions and efficiency mainly due to the inherently high flow resistance across the intake valves and inertia of the gas in the intake port. However, a later IVC timing such as the tested IVC-127 CAD ATDC, will then cause apparently backflow into the intake manifold as a result of the upward piston motion pushing the mass out of the cylinder before the valve closes.

Page 17 of 19 


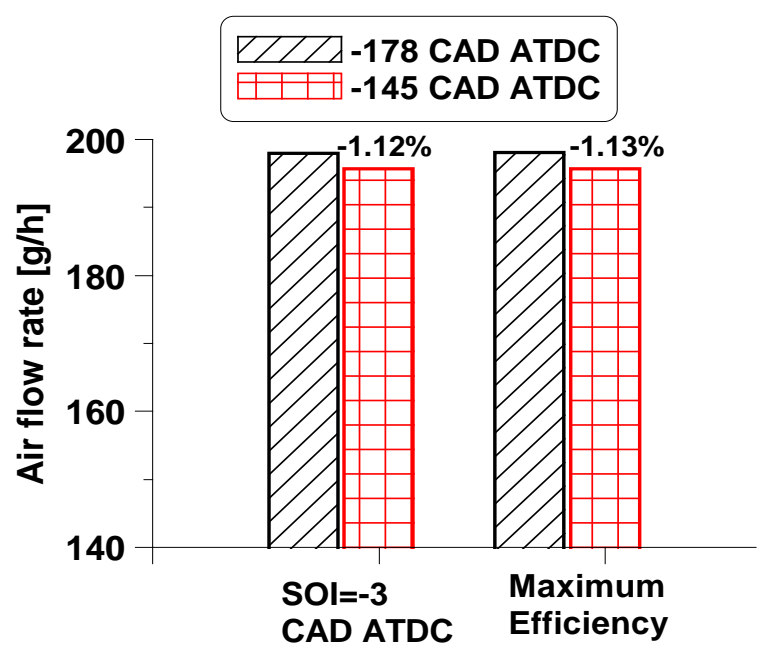

22. OK, from Figure 6 I get the following:

Miller cycle constant fuel injection timing - less air (higher equivalence ratios?), lower combustion temperatures \& pressures, longer combustion process; hence, less NOx potential, but more CO/HC/PM potential. Now, this is buffeted slightly for the optimized case by having earlier combustion where NOx should increase and CO/HC/PM will decrease.

EGR - same thing

In other words, please have a more complete discussion

Thanks for your suggestion, a more complete discussion has been added to the part of Engine Performance. According to a previous study [26] by using an one-dimensional engine simulation model to calculate the averaged in-cylinder gas temperatures and flame temperatures, it showed that the use of Miller cycle led to higher average combustion temperature due to the reduced total in-cylinder gas heat capacity, while lower flame

temperature due to the lower effective compression ratio and slower combustion process. However, the use of EGR led to lower average combustion temperature and flame temperature, and was more effective in reducing flame temperature than Miller cycle. By optimizing the injection timing, both EGR and Miller cycle strategies allowed for higher efficiency and lower emissions at the same levels of NOx emissions.

23. As lambda decreases, adiabatic flame temperatures rise; hence, NOx potential goes up...if you are moving towards the lambda of highest NOx potential (est. 1.3?). Otherwise, you are falling away from NOx potential. Please discuss.

As discussed above, both EGR and Miller cycle strategies led to lower adiabatic flame temperatures and thus NOx emissions.

24. EGR: "lower heat transfer loss" - won't this improve thermal efficiency? I agree that the prolonged combustion duration leads to a lower efficiency.

The slightly lower indicated efficiency in the EGR strategy was the net result of these two counteracting effects of the prolonged combustion duration and lower heat transfer loss.

25. Last sentence: "As such, the higher heat transfer loss and longer combustion duration..." The Miller cycle leads to a higher heat transfer loss, but you state that EGR leads to a lower heat transfer loss; hence, this sentence is confusing as written.

Thanks, this has been modified as "As such, the combined effects of the net heat transfer loss and longer combustion duration as well as the late combustion process accounted for the lower net indicated efficiency in the combined strategy of Miller cycle with EGR at high engine loads”.

26. "Miller cycle led to lower charger and combustion temperatures." But, didn't you just state that lambda increased resulting in higher combustion temperatures in the previous section? You are contradicting yourself, make sure to describe items fully and be consistent between sections. Then, you go into discussing how soot emissions were less affected by a sufficiently high lambda. So, NOx decreases because of a low combustion temperature, but soot is not affected because combustion remains hot? This is all confusing and not written clearly.

a. The first part has been revised as "Miller cycle led to lower in-cylinder charge and flame temperatures." And "lambda decreased resulting in higher average combustion temperature.”

b. At baseline IVC of -178 CAD ATDC, the dilution and higher heat capacity introduced by EGR lead to lower levels of NOx. However, the use of EGR has less impact on soot emissions due to the sufficiently high lambda which ensured a more complete oxidation for soot.

Page 18 of 19

7/20/2015 
27. Also, lambda lower than 1.2 still is oxygen rich, correct? But, here I assume you are infringing on the engine mixing limit, which is why you had to improve mixing.

When lambda lower than 1.2, there is insufficient oxygen for combustion and the local rich region is increased, which requires higher intake boost pressure or rail pressure to improve air-fuel mixing.

28. EGR also increased lambda; hence, this can make it hotter, right? Therefore, EGR increases lambda making it hotter; however, its effect as a diluent overcomes this potential, subsequently lowering combustion temperatures. Make sure to discuss the entire picture.

As shown in Figure 7, the use of EGR reduced lambda mainly due to the dilution effect. The combustion temperature decreased is attributed to the higher heat capacity introduced by EGR.

29. I did not analyze the CO, HC, NOx-soot, and NOx-ISFC tradeoff discussion because the picture (to me) is not clear at this point since there are conflictions present in the analysis.

Cost-benefit

30. Interesting section, very good.

Thank you.

Conclusions:

31. I agree that reducing the compression ratio lowered temperatures...but, lambda decreased that could raise the combustion temperature. Again, a full discussion is required.

Since the intake boost pressures were kept constant over the study, the in-cylinder air mass dropped as IVC timing was delayed, leading to a lower heat capacity and hence higher in-cylinder average combustion temperature. However, the lower compression pressure and temperature as well as the in-cylinder oxygen availability decreased the peak combustion temperature (flame temperature).

32. Overall, conclusions are good, but may need to change slightly based on the discussion in the earlier sections.

Thanks very much for your kind suggestions. It has been corrected accordingly. 